\title{
Research effort is preserved in plan to close London Zoo
}

London. Research at London Zoo will continue unaffected by the decision to close the Regent's Park site to the public at the end of September (see Commentary on page 621). All the same, research staff are supporting efforts by their colleagues to put together a survival package based on the zoo's role as a conservation centre.

The situation has been carried over from last year's crisis (see Nature 350, 453; 1991), which arose when the Zoological Society of London, which manages the zoo, announced that reductions in staff and services and additional government support were needed to keep the zoo open. Although the government did not provide any more money, the publicity afforded by the crisis increased attendance sufficiently to allow management to abandon its original plan. A 'breakeven' budget was implemented in March, but it has proved difficult to sustain. The zoo now faces an annual deficit of $£ 2$ million (US $\$ 3.5$ million), and the society says that it will have to close the zoo in order to maintain its other activities.

The zoo's research, carried out at the Institute of Zoology, will be affected very little by the closure. The work does not depend on the animals at the Regent's Park site, and relies instead on field work and cooperative efforts with other zoos and wildlife parks. However, the staff at the institute have strongly supported the London Zoo Survival Group, which includes some 80 per cent of the zoo's 240 employees. The group's conservation rescue plan would allow the researchers to maintain a close link with an active animal collection.

The institute is largely immune from the zoo's financial crisis. It receives $£ 1.3$ million a year from the Universities Funding Council, via the University of London, and has grant income of $£ 827,000$ from sources such as the research councils and the Royal Society for the Prevention of Cruelty to Animals.

The activities that the society says it is protecting by closing the zoo include conservation projects overseas, in other zoos and at its other site, the Whipsnade Wild Animal Park. However, zoo staff claim that much conservation work that is taking place as part of the curatorial process will be lost if the animals leave. Of particular interest is the insect house, where a number of large, genetically diverse populations of endangered species are being preserved for reintroduction into protected habitats. These include Mexican red-kneed bird-eating spiders and wart biters, a rare species of giant British cricket.

Gaining control of the zoo will be the crucial step for the survival group. With representatives from all sections of the zoo's staff the group also claims a sizeable following among the fellows of the Zoological Society, with whom the decision ultimately rests.

Chief among the group's complaints is that the zoo management has failed to publicize the zoo's activities as a conservation body. By advertising a trip to the zoo as a "good day out", says Doug Richardson of the group, the zoo is out of step with current public opinion towards animals in captivity. The survival group feels that an appropriate publicity campaign would draw the necessary financial support from public and private sources.

However, the most prominent external package to rescue the zoo would turn it even more into a theme park. New Zoo Developments (NZD), a consortium consisting of the Laing construction company, bankers Samuel Montagu and US designers Cambridge Seven Associates, has proposed a $£ 61$ million scheme which would include a rainforest pavilion, a coral-reef aquarium with an underwater tunnel for visitors and a number of other naturalistic settings for the animals.

Ian Mundell

\section{Lab death blamed on gas build-up}

Washington. The explosion of a 'cold fusion' cell at the Stanford Research Institute (SRI) in California earlier this year, which killed researcher Andrew Riley (see Nature $355,102 ; 1992)$, has been attributed to an unnoticed build-up of oxygen and deuterium inside the cell. That conclusion, based on a five-month investigation, dispels speculation that the explosion might in some way have been related to excess heat generated by the phenomenon itself.

The explosion occurred in a closed calorimetric cell, in which oxygen and deuterium liberated by the electrochemical reaction were normally recombined into water by a platinum catalyst. An expert team assembled by SRI concluded that the catalyst failed after 800 hours of running, allowing the gases to accumulate, and that the buildup of pressure forced a piece of teflon into a wire-hole that would otherwise have allowed the gases to escape.

The precise cause of the explosion could not be pinned down, but the report speculates that when Riley moved the cell, part of the platinum catalyst was re-exposed and began to work again, growing hot and eventually igniting the gas mixture.

David Lindley

\section{New Zealand tries to bring science closer to industry}

Sydney. The New Zealand government is overhauling the way in which science is organized in an effort to encourage industry to invest more heavily in research and to increase links between government scientists and the private sector.

On 1 July, the Department of Scientific and Industrial Research (DSIR), the largest government research organization, will combine its research operations with those of other government departments to form ten private companies wholly owned by the government. The companies, to be called Crown Research Institutes, will employ about 3,000 scientists. About 70 researchers will lose their jobs in the move, which involves the science divisions of the Ministries of Forestry and of Agriculture and Fisheries, as well as the Meteorological Service and the DSIR.

The reorganization will free government scientists from cumbersome procedures and severe restrictions on their commercial activities that included a prohibition on receiving royalties from their inventions. The new structure will allow individual institutes to carry out such activities as contract research, joint ventures and applied research with industrial partners.

Apart from making it easier for government scientists to attract private funds and to accept contract work, the new arrangement is intended to improve outside access to government research facilities. This access, the government hopes, will also inspire industry to increase its present low level of spending on research and development.

The changes will also affect the way in which government scientists are funded. Instead of giving money directly to the institutes in a block grant, the government will require scientists to submit proposals to a separate set of bureaucrats in the Ministry of Science. The money will be allocated in grants from a Public Good Science Fund. The fund will contain all but NZ\$185 million (US\$100 million) of the NZ\$435 million that the government spends on science. About NZ\$110 million is given to university faculty for basic research, and the rest is spent on medical and military research.

The new arrangement, a reflection of the ruling National Party's belief that public servants who control funds must be separated from those who spend the money, will force institutes to compete against one another for funding. A committee will select the best proposals.

The reorganization will not increase government spending on research. But it is expected to stabilize for several years the level of funding after a decade of declining support for science.
Mark Lawson 